\title{
SYNTHESIS OF METAL OXIDE-BASED
} NANOCOMPOSITES AND MULTICOMPONENT COMPOUNDS USING LAYER-BY-LAYER METHOD AND PROSPECTS FOR THEIR APPLICATION

\author{
G. Korotcenkova*, B. K. Choa, L. B. Gulinab , V. P. Tolstoy \\ aGwangju Institute of Science and Technology, Gwangju, Rep. of \\ Korea \\ bSaint Petersburg State University, Saint Petersburg, Russia
}

Article history

Received

15 August 2014

Received in revised form

17 April 2015

Accepted

21 June 2015

*Corresponding author ghkoro@gist.ac.kr

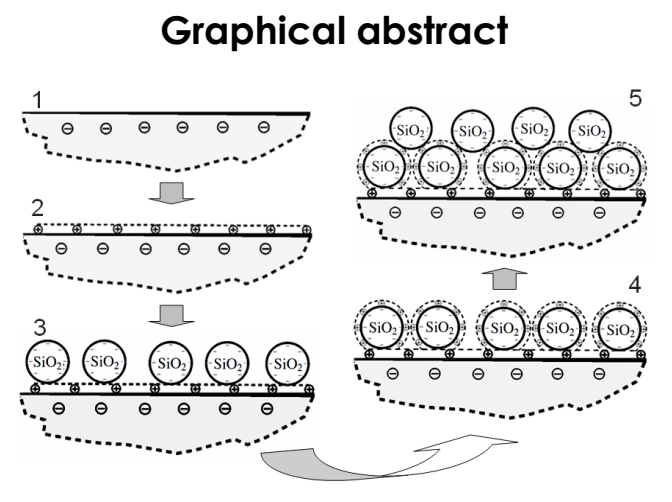

Abstract
The ability of Layer-by-Layer (LbL) or Successive lonic Layer Deposition
(SILD) technology to synthesize the layers of nanocomposites, "hybrid"
structures and multicomponent metal oxides on various substrates is being
discussed in this report. It was shown that concentration and $\mathrm{PH}$ of the
solutions used, the processing time, and the number of the LbL (SILD)
cycles were the main parameters of this process. It was made a conclusion
that coatings formed by LbL technology can be used in gas sensors and
catalysis for the surface functionalization, in membranes and filters for the
pore size controlling, in solar cells for the solar energy conversion, in medicine
for the formation of bactericidal coatings, and so on.
Keywords: Nanocomposites, LbL synthesis, SILD, deposition, characterization

(c) 2015 Penerbit UTM Press. All rights reserved

\subsection{INTRODUCTION}

Currently, the synthesis of multicomponent materials' nanolayers and nanostructures, composed of nanoparticles of inorganic solids, is of great interest [14]. These coverings can significantly change the surface properties of solids and, therefore, they can be widely used for optimization of various devices and processes. In particular, it was established that unique physical-chemical properties such as optical, electronic, catalytic, mechanical, and chemical ones can be obtained by advanced nanocomposites synthesized from different materials. For example, metallic and metal-oxide nanoparticles incorporated in various matrixes are capable to increase the activities of many chemical reactions due to the high ratio of the surface atoms with free valences to the total number of atoms in the cluster or nanoparticle [5]. As a result, one can obtain an ideal platform for designing chemical sensors and catalysts [6-8]. It was found that transition to nanocomposites could also improve mechanical properties and promote stabilization of the basic material parameters [9].

A variety of methods such as sol-gel technology, a spray pyrolysis deposition, thermal evaporation, chemical vapor deposition (CVD), a laser ablation, a magnetron sputtering, etc., can be used for synthesizing nanolayers of multicomponent materials [10-13]. However, very often traditional approaches to synthesis and deposition of multicomponent materials are not effective. Many of those methods are very cumbersome, expensive and inefficient for the complex materials deposition. Therefore, recently it was shown a special interest in wet chemical methods [14]. 
This happened because these methods provide conducting of the deposition process under so-called "mild chemistry" conditions, and allow performing the synthesis of required layers at room temperature. As a consequence, equipment and the process of synthesis are being simplified, the list of synthesized objects expands, and it becomes possible to receive nanolayers of inorganic substances with specific properties. Layer-by-layer (LbL) synthesis or Successive Ionic Layer Deposition (SILD) is one of such wet chemical methods [15-18]. LbL is also known as Successive Ionic Layer Adsorption and Reaction (SILAR) method [19]. The main feature of this method is successive and multiple treatment of the substrate surface by solutions containing two reagents. These reagents are the salts, that are the sources of cations and anions, which after interaction on the substrate surface produce either noble metals or poorly soluble compounds [16]. The substrate in this case acts alternately as a cation and anion exchanger. Substrate washing in suitable solvent is necessary to leave on the substrate surface only newly formed monolayer of required substance. As a result of such successive treatment, a layered control of composition and the size control of deposited particles at the nanometer scale can be achieved. Indicated sequence of treatments, which ends by the formation of a layer of the desired poorly soluble compound, is one deposition cycle. Ellipsometric measurements have shown that after each LbL (SILD) cycle a layer with average thickness of 0.4-1.5 nm could be deposited [20]. Upon multiple repetition of the adsorption reactions, the layer thickness increases in proportion with the number of treatment cycles. Thus, the LbL (SILD) method, employing separate and multiple stages of adsorption and reduction/oxidation of adsorbed species, has considerable potential in controlling the film thickness and the size of the deposited nanoparticles with a high precision via the number of ionic deposition cycles. Number of deposition cycles to be carried out depends on the desired layer thickness.

Experience has shown that LbL deposition could be conducted in a simple apparatus at room temperature and at atmospheric pressure. In particular, the successive steps could be made using simple robotic system. For deposition one can use ordinary inexpensive precursors and solutions with $\mathrm{pH}$ close to neutral $[19,20]$. In addition, this method does not require electrical current. Thus, LbL (SILD) process can be considered as relatively cheap technology. Moreover, particles used for the surface modification can present in the solution in a suspension state. As a result, nanolayers can be deposited on solid surfaces of any shape, including porous materials, disperse grains (powders) and nanowires. This ability of the LbL (SILD) technology to coat materials uniformly on a three dimensional surface under ambient conditions is main advantage of the LbL process as compared with expensive physical deposition methods.

Main goal of this report was the estimation of the LbL technology capabilities and the description of approaches which could be applied for forming nanolayers of multicomponent materials and nanocomposites promising for using in various applications. No doubts this problem is of interest, since in spite of the large number of publications, the deposition of the nanolayers of the multicomponent materials and nanocomposites on the required surface is still a great challenge.

\subsection{EXPERIMENTAL DETAILS}

\subsection{Synthesis}

As reactants for conducting the LbL synthesis we have used chemicals obtained from Ltd. Aurat (Russia), Vekton (Russia), and Aldrich. Working water solutions with required concentrations were prepared directly before synthesis. Milli-Q high pure water with resistivity exceeding $18 \mathrm{M} \Omega$ was used for a solution preparation and for washing procedure as well. For different experiments we have been using substrates such as fused silica of KV brand, single-crystal silicon wafers, or the $\mathrm{SnO}_{2}$ and $\mathrm{In}_{2} \mathrm{O}_{3}$ films deposited by spray pyrolysis. While conducting synthesis using the LbL process, the choice of precursor concentrations in the solutions used was based on our experience obtained when designing the technology of metal oxides and the noble metal synthesis. As a rule, concentration of reagents in solutions varied in the range from $0.001 \mathrm{M}$ to $0.1 \mathrm{M}$. It has been found that indicated concentrations provided an acceptable process duration required for the formation of nanolayers with desired thickness. Experiment has shown $[16,20]$ that the treatment time in each solution should be in the range of 0.5 - 2 minutes. In particular, in the initial experiments, the time of treatment in a solution of a reducing agent was 2 min. Duration of the subsequent washing with water was equaled 1-2 min.

One should note that it is rather difficult to determine optimal parameters for a synthesis by the LbL deposition method. Operations seem to be simple, but the process by itself has multiple stage character. Therefore, it is necessary to control ten and more synthesis conditions including, for example, concentration and $\mathrm{pH}$ of several reagent solutions, $\mathrm{pH}$ of washing liquids, the treatment duration, etc. The main difficulty of the metal-oxygen layers synthesis by ion deposition using metal salt solutions is a complexity of achieving conditions of irreversible adsorption of metal cations initially on the support surface and after that, on the surface of the layer synthesized. It is also essential that the conditions of the cations adsorption on the surface of the substrate and on the surface of synthesized layer are different, and this fact should be taken into account when selecting the synthesis conditions. Therefore, the development of synthesis technology should follow a route proposed in Figure 1. 


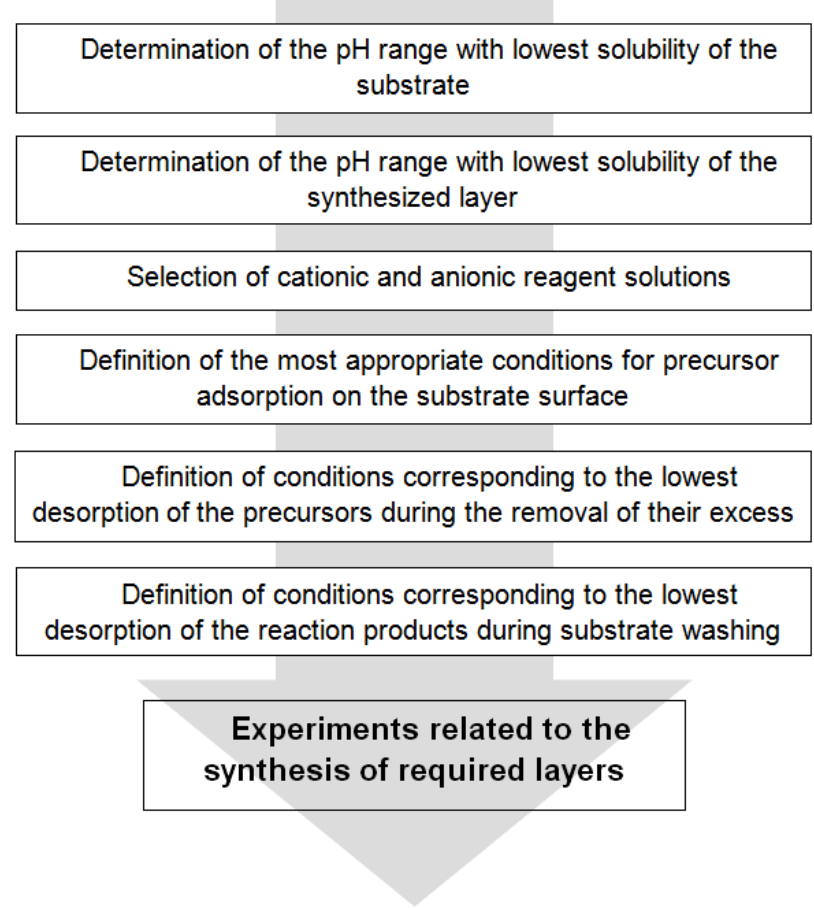

Figure 1 Diagram illustrating desired sequence in computations and experiments during selecting conditions of the nanolayers synthesis

Modeling of a reactions involved in the process of $\mathrm{LbL}$ can be conducted using computer programs such as Visual Minteq (http://epa.gov./ceampubl/mmedia/minteq/index.ht m) and Hydra-Medusa (http://www.kemi.kth.se/medusa), which related to simulation of hydrochemical equilibrium in solutions. While using these programs, one can determine the $\mathrm{pH}$ range of the lowest solubility of the substrate, the lowest solubility of the synthesized layer, and the conditions of their mutual coexistence. In Figure 2 one can find one of the examples of the selection conditions of metal oxide layer synthesis on the quartz substrate. Calculations were made for the $\mathrm{SiO}_{2}-\mathrm{ZrO}_{2}$ system.

From the results shown in Figure 2, it is seen that the quartz substrate and the synthesized layer $\mathrm{ZrO}_{2} \cdot \mathrm{nH}_{2} \mathrm{O}$ have the lowest solubility in the $\mathrm{pH}$ range of 2.0-9.0 and 3.0-9.5, correspondingly. It is obvious that using a $\mathrm{ZrOCl}_{2}$ solution with equilibrium $\mathrm{pH}$ of approximately 2.0 as a reactant in the $\mathrm{ZrO}_{2}$ synthesis will lead to dissolution of the $\mathrm{ZrO}_{2}$ layer synthesized in the previous LbL cycle. At the same time, the application of $\mathrm{K}_{2} \mathrm{ZrF}_{6}$ solution with equilibrium $\mathrm{pH}$ of about 4.0 gives a possibility to conduct synthesis in the $\mathrm{pH}$ range corresponding to the lowest solubility of the synthesized $\mathrm{ZrO}_{2}$ layer. Other reagents, such as solutions of $\mathrm{Y}\left(\mathrm{NO}_{3}\right)_{3}$ or copper ammine complex, $\left[\mathrm{Cu}\left(\mathrm{NH}_{3}\right)_{4}\right]^{2+}$, also have an equilibrium $\mathrm{pH}$ in the region of the lowest solubility of the $\mathrm{ZrO}_{2} \cdot \mathrm{nH}_{2} \mathrm{O}$ layer, and therefore they can also be used in $\mathrm{ZrO}_{2}$ synthesis.

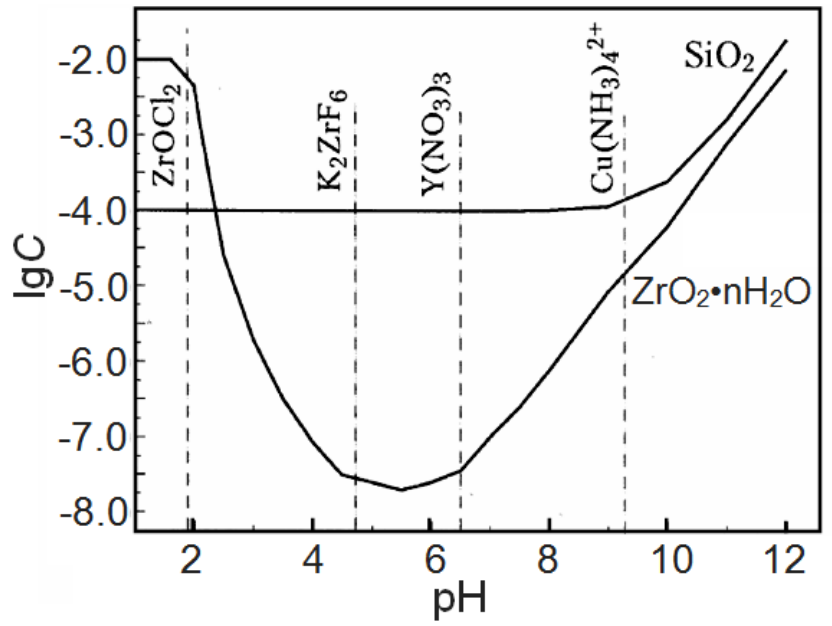

Figure 2 The calculated values of the changes in solubility of the substrate (quartz) and the synthesized layer $\left(\mathrm{ZrO}_{2} \cdot \mathrm{nH}_{2} \mathrm{O}\right)$ depending on $\mathrm{pH}$. Dashed lines show the equilibrium $\mathrm{pH}$ of reagent solutions with $C=0,001 \mathrm{M}$

Other example, illustrating the importance of the simulation of hydrochemical equilibrium in solutions for selection optimal conditions of the LbL synthesis, is shown in Figure 3. According to the results presented in this Figure, for the $\mathrm{SnO}_{2} \cdot \mathrm{nH}_{2} \mathrm{O}$ layer synthesis on the silica surface, it is necessary to use solutions of the $\mathrm{Sn}^{2+}$ salt with a $\mathrm{pH}$ of about 2.5, and during each LbL cycle to conduct $\mathrm{Sn}^{2+}$ oxidation in $\mathrm{Sn}^{4+}$ using solution of one of the oxidants. It is important that during this process the $\mathrm{pH}$ of the oxidizing solution should not exceed 9.5 since the calculations indicate a relatively high solubility of the silicon oxide substrate at high $\mathrm{pH}$ values.

Determination of optimal conditions of synthesis of multi-component nanolayers and multi-layers, consisting of two or more nanolayers of different composition, is more difficult because it is necessary to analyze the mutual influence of the much bigger number of reagents.

It should be noted that due to a great variety of physico-chemical properties of the materials used in various devices and processes, it was not possible to find any universal reaction which could be used for deposition of all required materials. Experience has shown that in almost every case it was necessary to solve a specific task $[15,16,21,22]$. Table 1 systematizes the reactions that have been used in our experiments.

\subsection{Structure and Morphology Characterization}

The synthesized layers have been studied by using scanning electron microscopy (SEM), scanning ion microscopy (SIM), X-ray diffraction (XRD), and various methods of spectroscopy. 


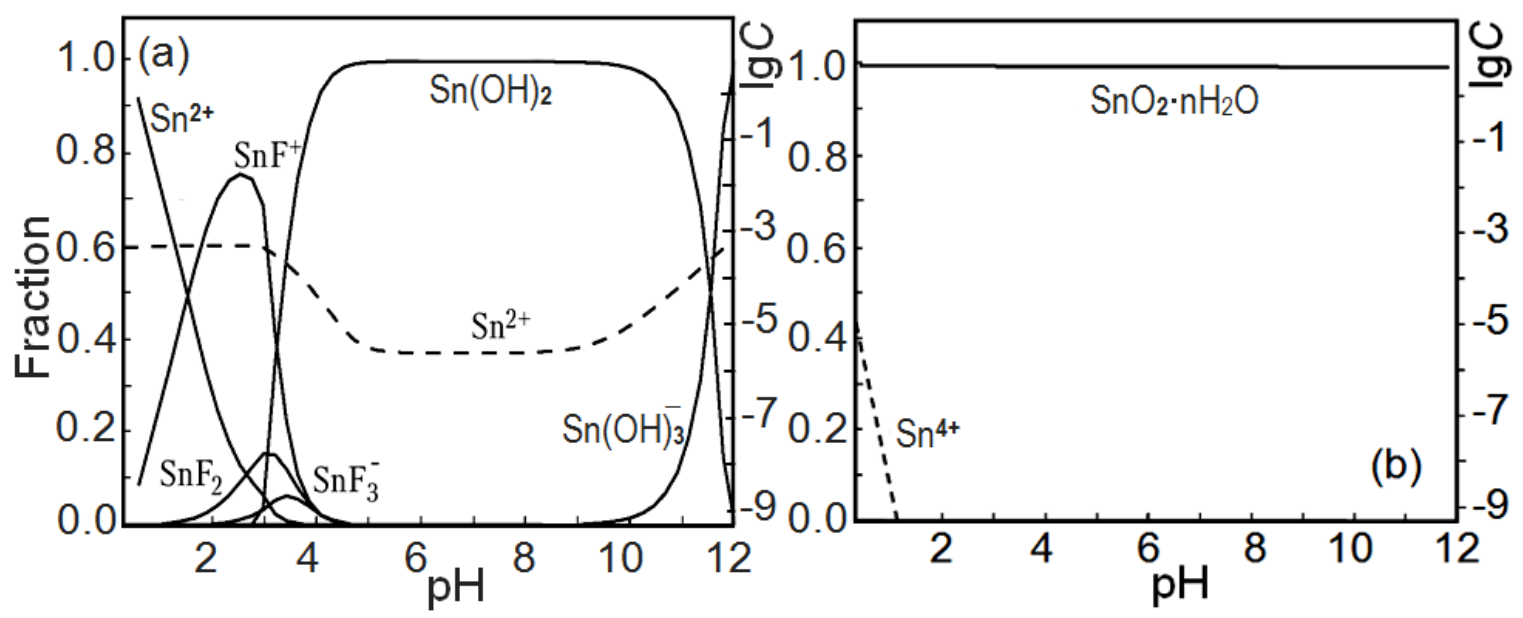

Figure 3 Diagrams of hydro-complexes is illustrating the changes in calculated values of the mole fractions of different salt

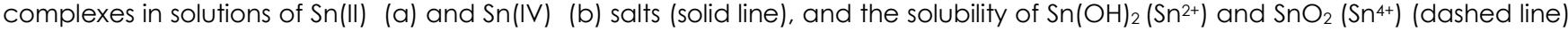
versus $\mathrm{pH} . \mathrm{C}_{\mathrm{Sn}^{2+}}=C_{\mathrm{Sn}^{4+}}=0.001$

Table 1 Reactions used for nanolayers forming during the SILD process of inorganic materials.

\begin{tabular}{|c|c|c|}
\hline $\begin{array}{l}\text { Route } \\
\text { number }\end{array}$ & Reactions used in LbL (SILD) processes & Examples of synthesized compounds \\
\hline 1 & $\begin{array}{l}\text { Reactions without changes in the oxidation } \\
\text { states of ions }\end{array}$ & $\begin{array}{l}\text { Poorly soluble sulfides, selenides, tungstates, } \\
\text { vanadates of metals, etc.. }\end{array}$ \\
\hline 2 & $\begin{array}{l}\text { Reactions in which the oxidation of the metal } \\
\text { cations occurs }\end{array}$ & $\begin{array}{l}\text { Metal oxides and hydroxides, such as } \\
\mathrm{SnO}_{2} \cdot \mathrm{nH}_{2} \mathrm{O}, \mathrm{CeO}_{2} \cdot \mathrm{nH}_{2} \mathrm{O}, \mathrm{FeOOH} \text {, etc.. }\end{array}$ \\
\hline 3 & $\begin{array}{l}\text { Reactions in which the reduction of the metal } \\
\text { ions takes place }\end{array}$ & $\begin{array}{l}\text { Nanoparticles and nanolayers of noble metals } \\
\text { such as } \mathrm{Ag}, \mathrm{Au} \text {, etc.. }\end{array}$ \\
\hline 4 & $\begin{array}{l}\text { Reactions in which the oxidation of metal } \\
\text { cations and reduction of anions takes place }\end{array}$ & $\begin{array}{l}\text { Nanocomposites such as } \mathrm{Au}_{x}-\mathrm{SnO}_{2}, \mathrm{Ag}_{\mathrm{x}}-\mathrm{SnO}_{2} \text {, } \\
\mathrm{Ag}_{\mathrm{x}}-\mathrm{MnO}_{2} \text {, etc.. }\end{array}$ \\
\hline
\end{tabular}

In particular, the films morphology was monitored using a Philips XL30 ESEM and FEI Nova Nanolab SEM/FIB scanning electron microscopes. SIM investigations were performed with scanning helium ion microscope (HIM) Zeiss Orion. All SEM and HIM images were obtained in secondary electron detection mode using acceleration voltage 10-30 kV. Thickness of the layers for the samples deposited on the silicon surface was measured by ellipsometry. Scanning electron microscope (SEM) Zeiss Merlin equipped with Oxford instruments Inca X-act EDX detector for X-ray microanalysis, as well as spectra of UV diffuse reflection, IR spectroscopy and X-ray photoelectron (XPS) spectroscopy were used for characterization of the surface composition. XPS spectra were collected from an ultrahigh vacuum system equipped with the hemispherical electrostatic analyzer Omicron EA125 with the MgKa line ( $\mathrm{hv}=1253.6 \mathrm{eV})$ for excitation. The element lines were recorded in detail with band pass energy of $20 \mathrm{eV}$. For some XPS experiments it was also applied Perkin-Elmer $5400 \mathrm{PHI}$ spectrometer operated with unmonochromatized MgKa irradiation, at a standard resolution of $0.8 \mathrm{eV}$. For FTIR study we have used a FTIR spectrometer Perkin-Elmer 1760X equipped with a DTGS detector. UV-vis spectra were measured with a Lambda-9 spectrophotometer (Perkin-Elmer) at a scanning rate of $50 \mathrm{~nm} / \mathrm{min}$ and a slit program of 2 $\mathrm{nm}$.

\subsection{RESULTS AND DISCUSSIONS}

\subsection{Multicomponent materials}

Experience has shown that all methods of layer-by-layer synthesis can be used for nano- and multi-layers formation. Classification of these methods is presented in Table 1.

It was established that using techniques, indicated in Table 1, it is possible to synthesize and form the coatings of a variety of materials from binary semiconductors and metal oxides such as $\ln _{2} \mathrm{~S}_{3}, \mathrm{Sb}_{2} \mathrm{~S}_{3}, \mathrm{PbS}, \mathrm{Fe}_{2} \mathrm{O}_{3}, \mathrm{ZnO}$, $\mathrm{SnO}_{2}$, etc. [16] to multi-component compounds, comprising three or more components. Some of these multicomponent compounds are listed in Table 2. Those compounds attracted interest because many of them could find application as catalysts, adsorbents, proton conductors, electron- and ion exchangers. XPS spectra of multicomponent material $\mathrm{Sn}_{16} \mathrm{PW}_{19} \mathrm{O}_{x} \cdot \mathrm{nH}_{2} \mathrm{O}$, deposited by LbL (SILD) are shown in Figure 4, while energy dispersive $\mathrm{X}$-ray spectrum of other multicomponent material, the cerium(IV) polytunstate layer, is shown in Figure 5. XPS and EDX spectra testify that synthesized layers are really multicomponent materials.

According to XRD measurements, films deposited by the LbL (SILD) method are fine-dispersed formations. Usually on XRD patterns of as-deposited films we did not observe any diffraction peaks. Only after annealing at 
$T_{a n}>300-500^{\circ} \mathrm{C}$, in XRD patterns we started observing XRD diffraction peaks, typical for polycrystalline material with crystallite size $<6-8 \mathrm{~nm}$. The shape analysis of XRD patterns has shown that the position of XRD diffraction peaks on XRD patterns and the ratio of these peaks intensities corresponded to metal oxides without any preferred orientation $[29,30]$.

Table 2 Multicomponent layers formed by LbL (SILD) methods

\begin{tabular}{|c|c|c|c|}
\hline Material & Route & Precursors & Ref. \\
\hline $\mathrm{BiVO}_{4} \cdot \mathrm{nH}_{2} \mathrm{O}$ & 1 & $\mathrm{BiOClO}_{4}$ and $\mathrm{NaVO}_{3}$ & 23 \\
\hline $\mathrm{Sn}_{1.6} \mathrm{MoO}_{x} \cdot \mathrm{nH}_{2} \mathrm{O}$ & 4 & $\mathrm{SnCl}_{2}$ and $\mathrm{Na}_{2} \mathrm{MOO}_{4}$ & 24 \\
\hline $\mathrm{Zr}_{2.6}(\mathrm{OH})_{x} \mathrm{PMO}_{8.0} \mathrm{Sn}_{1.9} \mathrm{O}_{y}$ & 1 & $\mathrm{Zr}\left(\mathrm{CH}_{3} \mathrm{COO}\right)_{4}$ and $\mathrm{SnCl}_{2}+\mathrm{H}_{3} \mathrm{PMO}_{12} \mathrm{O}_{40}$ & 25 \\
\hline $\mathrm{Sn}_{16} \mathrm{PW}_{19} \mathrm{O}_{x} \cdot \mathrm{nH}_{2} \mathrm{O}$ & 4 & $\mathrm{SnCl}_{2}$ and $\mathrm{H}_{3} \mathrm{PW}_{12} \mathrm{O}_{40}$ & 26 \\
\hline $\mathrm{Ce}_{0.8} \mathrm{WO}_{4} \cdot \mathrm{nH}_{2} \mathrm{O}$ & 1 & {$\left[\mathrm{Ce}\left(\mathrm{NH}_{3}\right)_{6}\right]\left(\mathrm{NO}_{3}\right)_{4}$ and $\left(\mathrm{NH}_{4}\right)_{2} \mathrm{WO}_{4}$} & 27 \\
\hline $\mathrm{LaXNbO}_{\mathrm{Y}}$ & 1 & $\mathrm{La}(\mathrm{OAC})_{3}$ and $\mathrm{Nb}(\mathrm{OH})_{5} \cdot \mathrm{H}_{2} \mathrm{O}_{2}$ & 21 \\
\hline $\mathrm{In}_{0.22} \mathrm{SnS}_{0.33}(\mathrm{OH})_{4}$ & 1 & $\mathrm{Na}_{4} \mathrm{SnS}_{4}$ and $\ln \left(\mathrm{NO}_{3}\right)_{3}$ or $\mathrm{InCl}_{3}$ & 28 \\
\hline
\end{tabular}
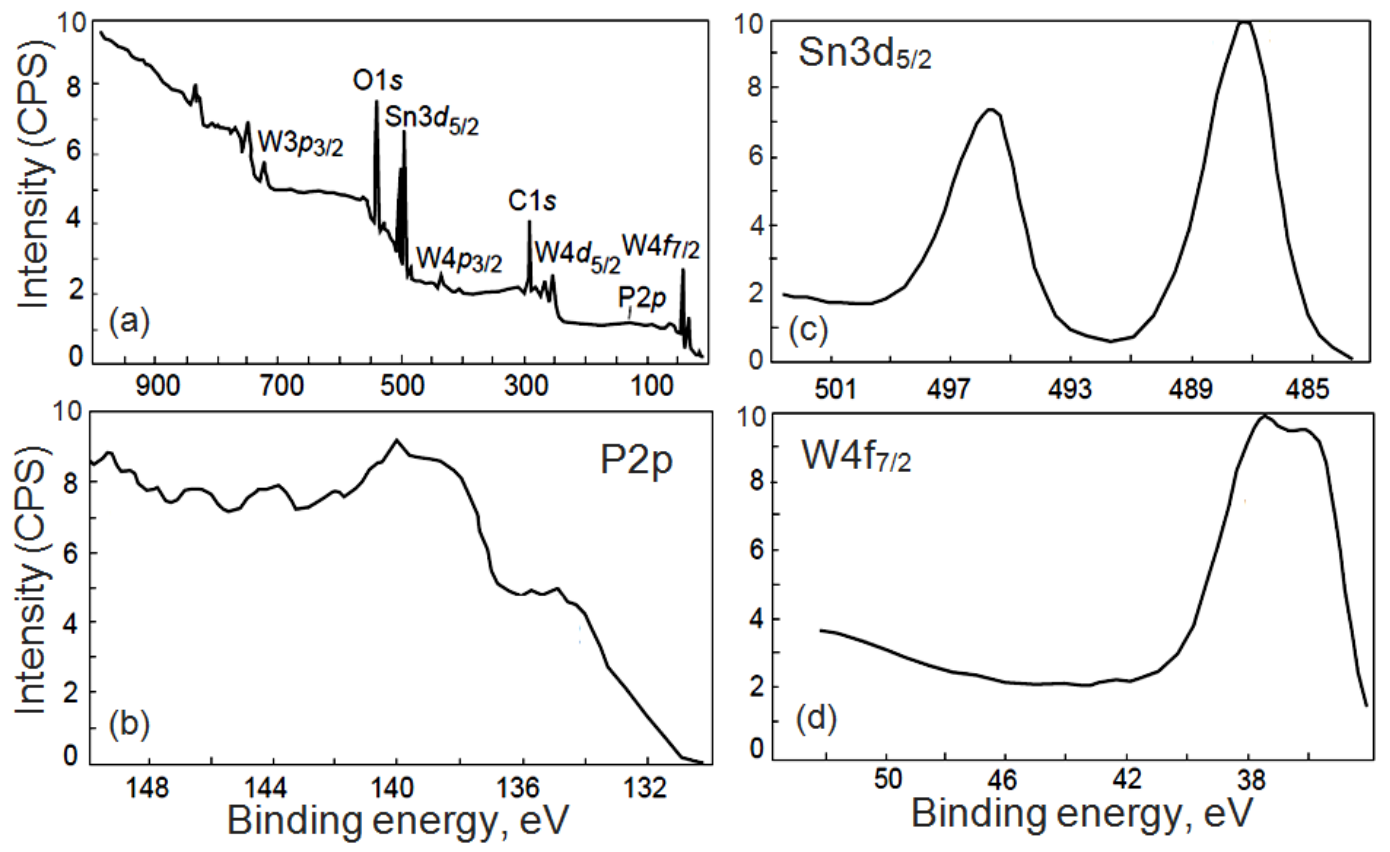

Figure 4 XPS spectra of the Sn-P-W-O nanolayer obtained on a surface of crystalline silicon by 30 LbL cycles: (a) full-range XPS spectra; $(b, c, d)$ XPS P2p, Sn3d and W4f core level spectra, correspondingly

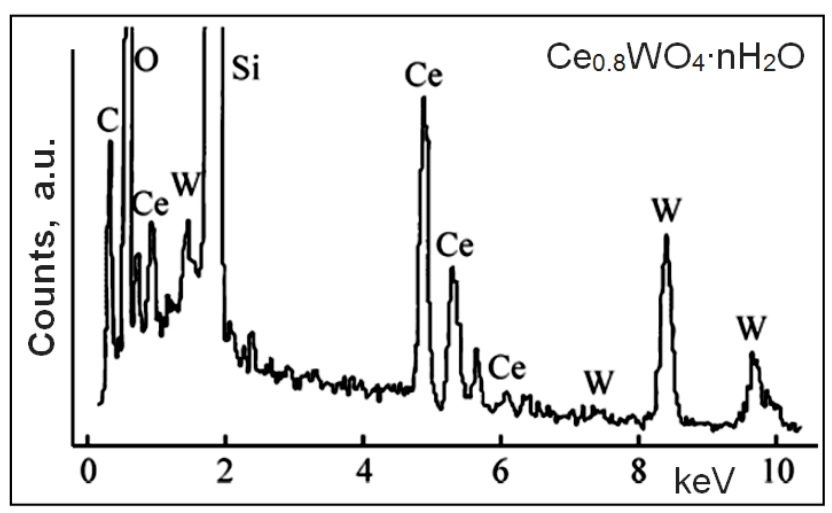

Figure 5 Energy dispersive X-ray spectrum of the cerium(IV) polytunstate layer synthesized on the silicon surface using 25 cycles
As it is seen in Figure 6, the morphology is determined by the nature of the synthesized material. It was established that the growth of the metal oxide layers took place through the formation of $2 D$ and $3 D$ precipitates, uniformly distributed along the surface. As a rule, continuous coating usually has been formed after 10-13 deposition cycles. The thickness of the continuous layer can vary from 15 to $50 \mathrm{~nm}$. It was also established that the layers deposited by the LbL method were characterized by strong agglomeration of the precipitates indicated above. According to SEM and AFM measurements, these agglomerates have spherical shape. SEM images also clearly indicate that the size of agglomerates goes up when the increasing of the metal oxide film thickness takes place. For example, for the $\mathrm{SnO}_{2}$ films deposited by the $\mathrm{LbL}$ method, the agglomerate sizes are being increased from 20 to $300 \mathrm{~nm}$ when the number of deposition cycles is enlarged from 10 to 40 . At the same time, the 
average size of precipitates weakly depends on the number of deposition cycles and is about 10-15 nm.
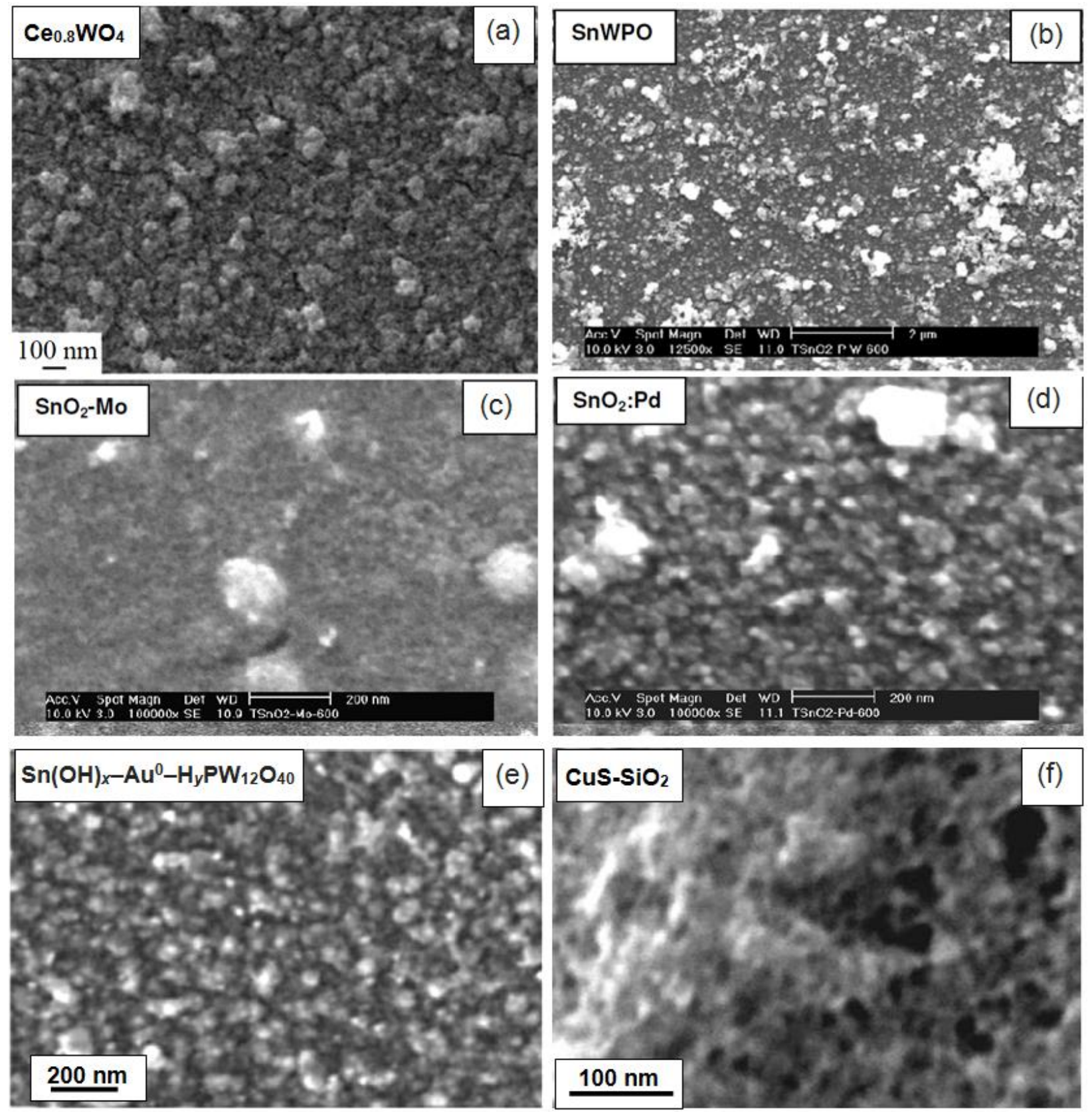

Figure 6 Typical SEM images of the layers synthesized on the surface of a silicon substrate by the LbL method using 12-25 cycles: (a) cerium(IV) polytunstate layer; (b) $\mathrm{Sn}_{16} \mathrm{PW}_{19} \mathrm{O}_{x} \cdot \mathrm{nH}_{2} \mathrm{O}$ films; (c) $\mathrm{Sn}_{1.6} \mathrm{MoO}_{x} \cdot \mathrm{nH}_{2} \mathrm{O}$; (d) $\mathrm{Pd}_{-} \mathrm{SnO}_{2}$ nanocomposite; (e) $\mathrm{Sn}(\mathrm{OH})_{x}-\mathrm{Au}^{0}-$ $\mathrm{H}_{y} \mathrm{PW}_{12} \mathrm{O}_{40}$ nanocomposite; (f) CuS-SiO 2 composite

It was also found that due to high agglomeration, films deposited by LbL have higher roughness in comparison with the roughness of the tin oxide films deposited by standard methods of the film deposition. For example, the $\mathrm{SnO}_{2}$ films deposited by the LbL method had 2-3 times higher roughness than the $\mathrm{SnO}_{2}$ films deposited by a spray pyrolysis method, and 3-4 times higher than the $\mathrm{SnO}_{2}$ films deposited by the low temperature sputtering technology and the electron beam evaporation.
FTIR spectroscopy showed that metal oxides asdeposited by the LbL method represented various forms of hydroxide, peroxide or hydrated metal oxide-based compounds [30]. However, after annealing at relatively low temperatures $\left(200-500^{\circ} \mathrm{C}\right)$, these compounds release both water and peroxide oxygen, and transform into corresponding oxides with appropriate film densification. This transition is clearly tracked in transformation of a FTIR spectra; sharp drop in the 
intensity of the water bands after annealing in air at 200 ${ }^{\circ} \mathrm{C}$ and disappearing $\delta(\mathrm{OH})$ bands in the $1500-1300 \mathrm{~cm}^{-}$ ${ }^{1}$ region after sample annealing at $500{ }^{\circ} \mathrm{C}$ take place.

\subsection{Noble Metal-based Nanocomposites}

It should be noted that synthesis of nanocomposites based on noble metals was of a special interest to us. As it is known, nanoclusters of noble metals such as Pd,
$\mathrm{Pt}, \mathrm{Au}, \mathrm{Rh}$ and $\mathrm{Ag}$, incorporated in a metal-oxide matrix increase catalytic activity of gas-sensing materials, change adsorption/desorption parameters, and promote the reducing operation temperature, increasing sensor response, enhancing the response rate, and improving sensor selectivity [31, 32]. Noble metal-based nanocomposites formed by the LbL methods are listed in Table 3.

Table 3 Noble metal-based nanocomposites formed by LbL (SILD) methods

\begin{tabular}{|c|c|c|c|c|}
\hline Material & Route & Precursors & $\mathrm{NM} / \mathrm{Me}, \%$ & Ref. \\
\hline $\mathrm{Ag}-\mathrm{MnO}_{2}$ & 4 & $\mathrm{AgNO}_{3}(\mathrm{pH}=9.0)$ and $\mathrm{Mn}(\mathrm{OAC})_{2}(\mathrm{pH}=7.5)$ & $\sim 70$ & 33 \\
\hline $\mathrm{Pd}-\mathrm{SnO}_{2}$ & 4 & $\mathrm{SnF}_{2}$ and $\mathrm{PdCl}_{2}$ & & \\
\hline $\mathrm{Au}-\mathrm{SnO}_{2}$ & 4 & $\mathrm{SnCl}_{2}$ and $\mathrm{HAuCl}_{4}$ & $\sim 50$ & 34 \\
\hline $\mathrm{Ag}-\mathrm{SnO}_{2}$ & 4 & $\mathrm{SnF}_{2}$ and $\left(\mathrm{AgNO}_{3}+\mathrm{Na}_{2} \mathrm{H}_{2} \mathrm{EDTA}\right)(\mathrm{pH}=6.0)$ & $\sim 60$ & 35 \\
\hline
\end{tabular}

As a rule, indicated composites were formed using reactions based on the oxidation and reduction of cations. At that it was found that for oxidation of adsorbed cations other metal cations could also be used. For example, while synthesizing the $\mathrm{Ag}_{\mathrm{x}} \mathrm{O}_{-}$ $\mathrm{MnO}_{2} \cdot \mathrm{nH}_{2} \mathrm{O}$ layers, a cation $\mathrm{Mn}^{2+}$ may be used as a reducing agent, and cations $\mathrm{Ag}^{+}$as an oxidant [33]. It is important that for these reagents there is $\mathrm{pH}$ range at which the products of the surface interaction of these cations, namely - $\mathrm{MnO}_{2}$ and $\mathrm{Ag}^{0}$, are poorly soluble. Experiment has shown that aqueous solutions of $\mathrm{Mn}\left(\mathrm{CH}_{3} \mathrm{COO}\right)_{2}$ and $\mathrm{AgNO}_{3}$ could be used as reactants in $\mathrm{Ag}^{0}-\mathrm{Mn}$-O-based nanolayers synthesis. In particular, it was found that the layer growth might occur while using $0.01 \mathrm{M}$ aqueous solutions of $\mathrm{Mn}\left(\mathrm{CH}_{3} \mathrm{COO}\right)_{2}$ with $\mathrm{a} \mathrm{pH}=$ 7.5 and $\mathrm{AgNO}_{3}$ with $\mathrm{pH}=8.5-9.0$. To shift the $\mathrm{pH}$ of the solution in the alkaline region the addition of $\mathrm{CH}_{3} \mathrm{COONa}$ was used for $\mathrm{Mn}\left(\mathrm{CH}_{3} \mathrm{COO}\right)_{2}$ solution, and $\mathrm{NH}_{4} \mathrm{ONa}$ for the solution of $\mathrm{AgNO}_{3}$.

The formation of the $\mathrm{Ag}_{\mathrm{x}} \mathrm{O}-\mathrm{MnO}_{2}$ composite was confirmed by X-ray spectroscopy. In the XPS spectra of synthesized layer (see Figure 7), the peak corresponding to $\mathrm{Mn}^{4+}(2 \mathrm{p} 3 / 2)$ ions of $\mathrm{MnO}_{2}$, and the peak corresponding to $\mathrm{Ag}^{0}$ (3d5/2) were observed. The ratio of $\mathrm{Ag}^{0} / \mathrm{MnO}_{2}$ concentrations in the layer was $\sim 0.7$.

When forming the $\mathrm{Au}-\mathrm{SnO}_{2}$ composite, the $\mathrm{HAuCl}_{4}$ solution was used as the oxidant [34]. The ratio of the $\mathrm{Au} / \mathrm{Sn}$ concentrations in the nanocomposite synthesized using this approach was close to 1, and the size of the $\mathrm{Au}^{0}$ nanoparticles after first deposition cycles was in the range of 3-40 nm. XPS spectra of the Au-SnO 2 nanocomposite are shown in Figure 8. They indicate that gold in the composite is in the metallic state. Tin oxide in the $\mathrm{Au}-\mathrm{SnO}_{2}$ composite, as in the case of deposition of the $\mathrm{SnO}_{2}$ layer, was either amorphous or fine dispersed even after annealing at temperatures of $400^{\circ} \mathrm{C}$.

Analysis of SEM images showed that the nanocomposites and multicompomponent materials discussed above had similar film morphology. Typical SEM images of the noble metal-based nanocomposites formed by the LbL methods are shown in Figure 6d, e. It was established that the growth of the metal oxide films during deposition took place through the growth of the agglomerates. For example, for the $\mathrm{SnO}_{2}-\mathrm{Au}$ nanocomposites the average size of agglomerates reached $\sim 100 \mathrm{~nm}$ after 16 deposition cycles.

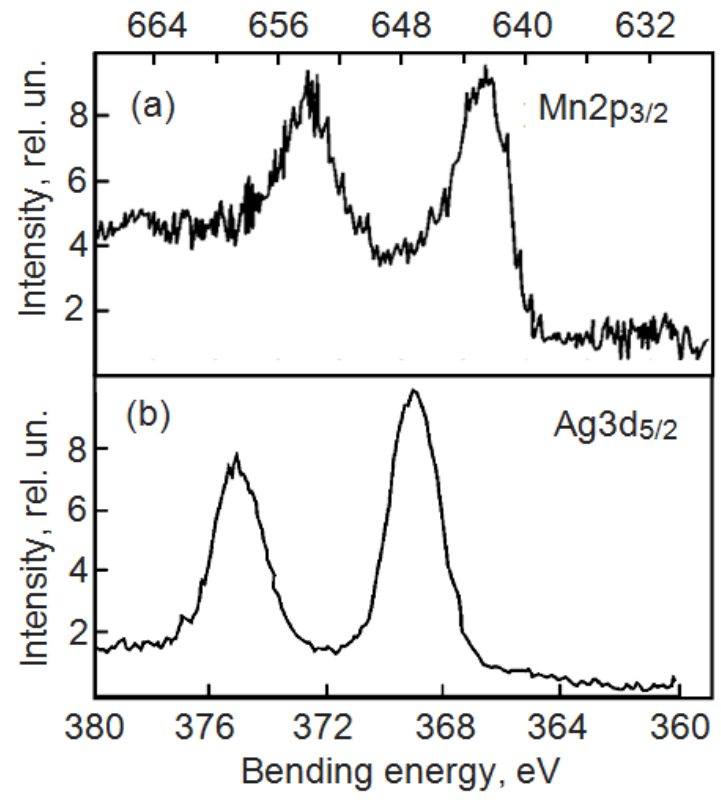

Figure 7 The core level XPS spectra of the $\mathrm{Ag}-\mathrm{MnO}_{2}$ nanocomposite 


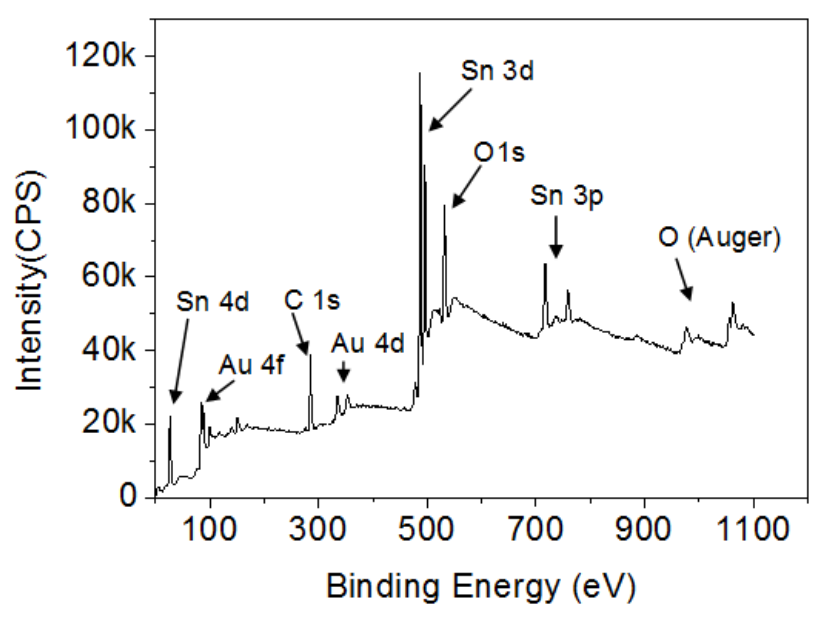

Figure 8 Full-range XPS spectra of the $\mathrm{SnO}_{2}-\mathrm{Au}$ nanocomposites deposited by the LbL method using 13 deposition cycles

However, one should note that nanocomposites that can be synthesized using this approach typically contain a high concentration of the noble metal, which can reach $50 \%$. For some applications, where clusters of noble metals with the size not exceeding 3-5 $\mathrm{nm}$ are required, this concentration is too high. To solve this problem, one can go to the separate deposition of composite's components. For example, initially the layer of metal oxide is being deposited and then the layer of the noble metal is deposited, or vice versa. In this case, the size of the noble metal particles is determined by the conditions of the adsorption and reduction of noble metals' ions, which do not depend on other reactions and which are easier to control. However, the solution of this problem requires further study. In addition, in this case the duration of deposition cycle will be significantly longer.

\section{3 $\mathrm{SiO}_{2}$-based Nanocomposites}

Another direction in synthesis, which is of interest for application in design of bio- and chemical sensors as well as in heterogeneous catalysis, is the formation of semiconductor and metal oxide-based composites, incorporating the $\mathrm{SiO}_{2}$ particles. Incorporation in the metal oxide or the semiconductor matrix of the $\mathrm{SiO}_{2}$ particles with the required size can give a significant increase in stability, porosity and the surface area, and thus help to improve the device parameters, important for such applications. The LbL technology opportunities for synthesizing such composites were evaluated by developing formation technology of the layers, listed in Table 4.

Table $4 \mathrm{SiO}_{2}$-based nanocomposites formed by LbL methods.

\begin{tabular}{lllll}
\hline Material & Route & Precursors & Ref. \\
\hline $\mathrm{CuO}_{x}-\mathrm{SiO}_{2}$ & $\mathrm{ICL}$ & Colloidal $\mathrm{SiO}_{2}$ solution + solution of $\mathrm{Cu}\left(\mathrm{CH}_{3} \mathrm{COO}\right)_{2}$ & 36 \\
\hline $\mathrm{CuS}-\mathrm{SiO}_{2}$ & $\mathrm{ICL}$ & Colloidal $\mathrm{SiO}_{2}$ solution + solution of $\mathrm{Cu}\left(\mathrm{CH}_{3} \mathrm{COO}\right)_{2}$ and $\mathrm{Na}_{2} \mathrm{~S}$ & 22 \\
\hline $\mathrm{Sb}_{2} \mathrm{~S}_{3}-\mathrm{SiO}_{2}$ & $\mathrm{CL}$ & Colloidal $\mathrm{SiO}_{2}$ solution + colloidal solution of $\mathrm{Sb}_{2} \mathrm{~S}_{5}$ & 37 \\
\hline $\mathrm{ICL}-$ lon-colloid layering; $\mathrm{CL}-$ Colloidal layering &
\end{tabular}

For the formation of nanocomposites indicated in Table 4 we have used the method of colloidal or ioncolloid layering. In particular, for the $\mathrm{CuO}_{x}-\mathrm{SiO}_{2}$ synthesis we applied a process based on the methodology proposed by ller [38]. This process includes a successive surface treatment with colloidal and "ionic" solutions. It was found that the $\mathrm{SiO}_{2}$ sol and a solution of $\mathrm{Cu}\left(\mathrm{CH}_{3} \mathrm{COO}\right)_{2}$ can act as colloidal and ionic solutions in this process. While processing in a solution of
$\mathrm{Cu}\left(\mathrm{CH}_{3} \mathrm{COO}\right)_{2}$, the adsorption of the copper cations on the substrate surface is being observed, and then these cations act as centers of attraction for the $\mathrm{SiO}_{2}$ colloidal particles in the step of substrate surface processing in colloidal solution. The mechanism of such composites formation is shown in Figure 9. SEM image of this layer is shown in Figure $6 f$. 


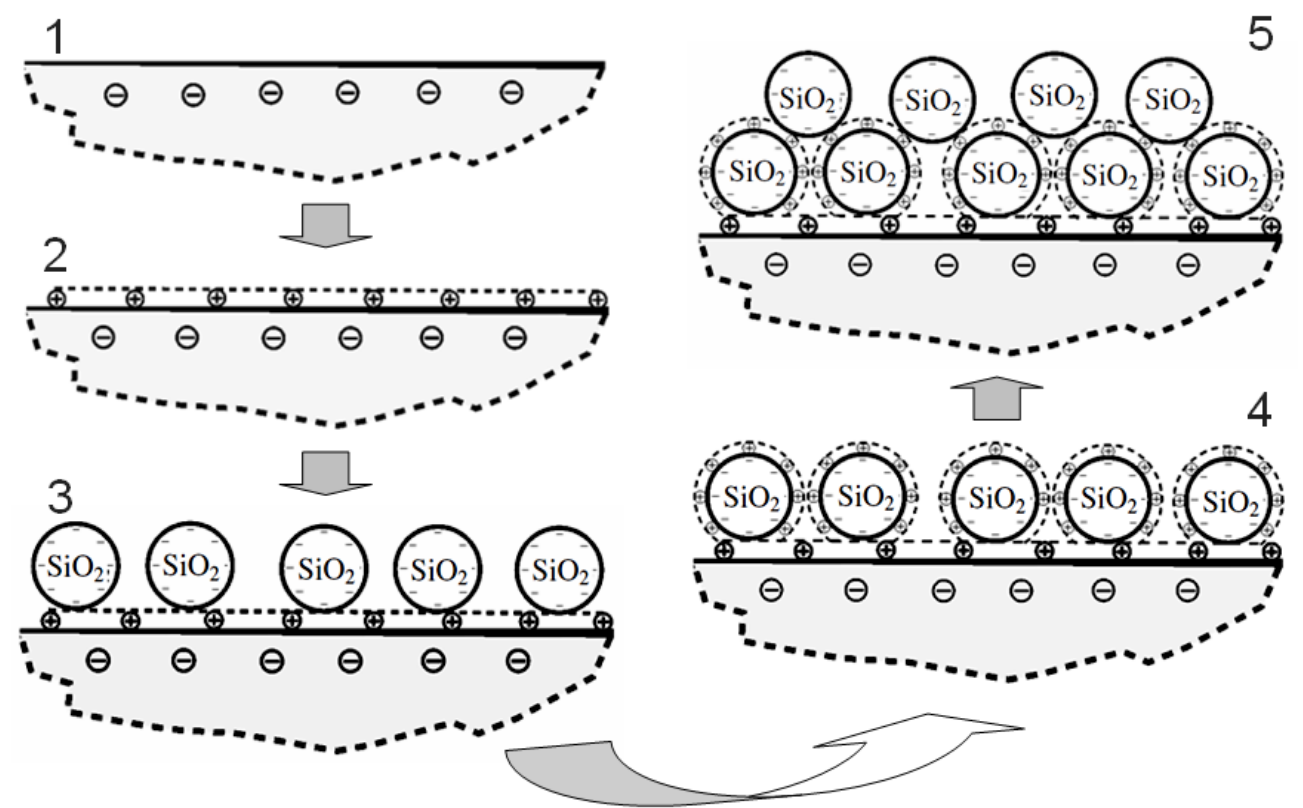

Figure 9 Schemes of the LbL (SILD) reactions involving the $\mathrm{SiO}_{2}$ colloidal particles and an $\mathrm{CU}$ (II) solution: (1) Initial substrate, $(2,4)$ after adsorption of $\mathrm{CU}(\mathrm{II})$ cations, $(3,5)$ after treatment in a colloidal solution, containing the $\mathrm{SiO}_{2}$ particles (stages of adagulation of colloidal $\mathrm{SiO}_{2}$ particles)

\subsection{Prospects for Applications}

As appears from the above discussions, the LbL (SILD) method does not possess high deposition rates in comparison with other chemical methods of deposition, such as electrochemical deposition, chemical deposition, etc. [39]. As it was shown above, the layer with average thickness of 0.5-1.5 nm can be formed using one deposition cycle. This means that if the layer with thickness of $1 \mu \mathrm{m}$ was required, it is necessary to conduct about $10^{3}$ cycles. Of course, it requires to conduct a long process, which strongly restricts the application of the LbL (SILD) technology for solving such tasks. However, it should be noted that there are many applications where thick coatings are not required. For example, a high deposition rate and thick coatings are not required for the surface modification in catalysis, chemical sensors and biosensors [40]. In these applications, where the surface functionalization of materials is being used, first of all a controlled deposition of nanoclusters and nanolayers is required. As it is known, in many cases for a better control of the surface chemistry it is essential to deposit either atoms or single molecular layers on the surface. This means that precise monitoring of size and composition of deposited clusters and nanolayers is more important for applications such as surface and structural engineering. This means that LbL method, which reveals indicated ability to control coating on the nano miter level, has great advantages in comparison with many other methods designed for the surface modification of various materials. Thus, from our point of view, the LbL-based technique has a potential as a new technology for designing new nanoscale and innovative functional nanomaterials with specific surface properties. In other words, the LbL method can be regarded as a versatile bottom-up nanofabrication technique which allows a variety of materials being incorporated within the film structures. This technology can be applied while fabricating chemical sensors and biosensors, various catalysts, membranes and filters, new surface coatings, particular bactericidal coatings, advanced drug design, smart materials, and so on.

For example, we have shown that metal oxides either synthesized or modified by the LbL method could be used for increasing sensitivity and selectivity of the $\mathrm{SnO}_{2-}$ based gas sensors [20,41]. Synthesized nanolayers may act as a gas sensing layers or as filters for oxidizing gases [42], promoting the improvement of exploitation parameters of reducing gas sensors working in real conditions, when the appearance of either ozone or nitrogen dioxide in the atmosphere is possible. The LbL technology could be also successfully implemented into fabrication of other types of catalytically active filters designed, for example, for the reduction of pollutant emissions from various combustion engines. This technology is accessible and simple and does not require a special skills as well as expensive and complicated experimental apparatus. Indicated features of LbL technology and an opportunity to deposit catalytically active materials on the developed surfaces, used as a support for heterogeneous catalysts, may contribute to a successful advancement of LbL technology to the market.

Taking into account that the LbL coatings can be deposited not only on planar substrates but also on colloids, nanoparticles and in the pores of various materials, the LbL technology can be also used for controlling the pore size in membranes. It is known that such membranes are needed in diverse areas of the chemical and biological fields for materials separation, controlled permeation and release of target materials, 
sensing, etc.. The benefits of the suggested technology can be considerably increased by the ability to form such coverings at room temperature.

It was established that the surface coatings, developed for protecting materials against the environment, can be also formed by using the LbL technology. In particular, it was shown that the layers synthesized using SILD technology improved the surface corrosion resistance of the plates of zinc, steel, silver, and other materials. Layers of the zinc chromate, synthesized by the LbL method, also allowed improving the heat resistance of the $\mathrm{Zn}$ coatings. It was established that the layers on the surface of the $\mathrm{Zn}$ coating, synthesized using the method of ionic layering, provided high protective properties of the $\mathrm{Zn}$ coatings even after heating at $150-200^{\circ} \mathrm{C}$, while the unmodified coating has already lost properties when the temperature of heating exceeded $80{ }^{\circ} \mathrm{C}$ (see Figure 10).

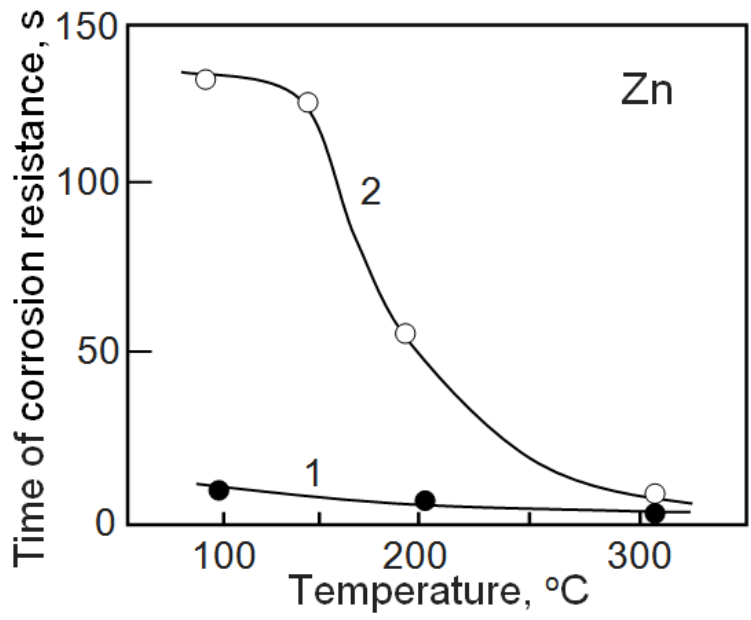

Figure 10 The change in corrosion resistance of $\mathrm{Zn}$ coating depending on the temperature of samples heating in air: 1 sample passivated in a solution of $\mathrm{CrO}_{3}, 2$ - sample processed in solutions of $\mathrm{Zn}\left(\mathrm{CH}_{3} \mathrm{COO}\right)_{2}$ and $\mathrm{Na}_{2} \mathrm{CrO}_{4}$ using 10 cycles of ionic layer deposition

We believe that the technology, discussed in present paper, is also of interest for scientists, designing sensors on the base of various porous materials such as $\mathrm{Si}, \mathrm{SiC}$, GaN [40,43], because the surface modification of porous semiconductors promotes a considerable surface reactivity and provides them an additional functionality. We have found that the gold clusters in the $\mathrm{Au}-\mathrm{SnO}_{2}$ nanocomposite are significantly more stable than clusters synthesized on a flat surface. It makes the $\mathrm{Au}-\mathrm{SnO}_{2}$ nanocomposite, having a large surface area, promising for use in biosensors based on a plasmon resonance. At the same time, the Ag-based nanocomposites, comprising silver nanoparticles, which show a high antimicrobial activity, can be used as an antimicrobial coating.

Various materials used in solar cells and fuel cells applications can be synthesized using the LbL (SILD) technique as well. For example, while using LbL one can prepare a composite polyelectrolyte multi-layer thin films on the membranes surface and thus minimize the methanol-crossover problem in a direct methanol fuel cells (DMFC) as demonstrated by Jiang et al. [44].

Core-shell multifunctional nanoparticles and multilayer films with unique physiochemical properties can be easily synthesized using the LbL technology. For example, the LbL method can be used for preparing films with incorporated quantum dots of II-VI compounds showing intense photoluminescence.

\subsection{SUMMARY AND FUTURE}

As a result of discussed studies, the synthesis conditions of various "hybrid" structures, multicomponent compounds and nanocomposites were established. It was found that concentration and $\mathrm{pH}$ of the solutions used, time of treatments, and the number of the LbL cycles were the main parameters of this process. It was shown that the "islet" mechanism of the layer growth and the formation of coatings in the hydrated form have been mainly realized during the LbL process. The transition to the oxide phase took place during annealing at $T_{\mathrm{an}}>250-300^{\circ} \mathrm{C}$.

It was made a conclusion that formed coatings could be used in gas sensing and catalysis for the surface functionalization; in membranes and filters for controlling pore size; in semiconductor cells for a solar energy conversion; in medicine for formation of bactericidal coatings, and so on. We believe that the LbL method due to its simple concept is applicable to a wide range of adaptations and could be used as a promising methodology for realization of various nanotechnologies and fundamental studies of physicochemical phenomena. We also hope that this report would be an incentive for further development of the LbL technology.

\section{Acknowledgments}

This work was supported by St. Petersburg State University (grant No. 12.38.259.2014), by the Russian Foundation for Basic Research (grant No. 15-03$08045 \mathrm{~A}$ ), and partly by the National Research Foundation (NRF) grants funded by the Korean government (No. 2011-0028736 and No. 2013-K000315), and by Basic Science Research Program through the NRF funded by the Ministry of Science, ICT and Future Planning of Korea (2012-R1A1A2041564).

\section{References}

[1] Cury Camargo, P. H. K. G. Satyanarayana, and F. Wypych. 2009. Nanocomposites: Synthesis, Structure, Properties and New Application Opportunities. Materials Research. 12: 1-39.

[2] Li, J., and J.Z. Zhang. 2009. Optical Properties and Applications of Hybrid Semiconductor Nanomaterials. Coordination Chemistry Reviews. 253: 3015-3041. 
[3] Moya, J.S., S. Lopez-Esteban, and C. Pecharroman. 2007. The Challenge of Ceramic/Metal Microcomposites and Nanocomposites. Progress in Material Science. 52: 1017-1090.

[4] Zhang, S., D. S. Yongqing, and F. H. Du. 2003. Recent Advances of Superhard Nanocomposite Coatings: A Review. Surface Coating Technology. 167: 13-119.

[5] Wachs, I. E. 2005. Recent Conceptual Advances in the Catalysis Science of Mixed Metal Oxide Catalytic Materials. Catalysis Today. 100: 79-94.

[6] Dudek, M. 2008. Composite oxide electrolytes for electrochemical devices. Advances in Material Science. 8: 15-30.

[7] Comini, E., M. Ferroni, V. Guidi, G. Faglia, G. Martinelli, and G. Sberveglieri. 2002. Nanostructured Mixed Oxides Compounds for Gas Sensing Applications. Sensors and Actuators B. 84: 26-32.

[8] Gas'kov, A., and M. Rumyantseva. 2009. Metal oxide Nanocomposites: Synthesis and Characterization in Relation with Gas Sensing Phenomena. In: Baraton, M. I. (ed.) Sensors for Environment, Health and Security. Dordrecht: Springer Science + Business Media B. V. 3-29.

[9] Konig, U. 1987. Deposition and Properties of Multicomponent Hard Coating. Surface Coating Technology. 33: 91-103.

[10] Willmott, P. R. 2004. Deposition of Complex Multielemental Thin Films. Progress in Surface Science. 76: 163-217.

[11] Jones, A. C., and P. O'Brien. 1997. CVD of Compound Semiconductors. Precursor Synthesis, Development and Applications. Weinheim: Wiley/VCH.

[12] Sakka, S. (ed.). 2004. Sol-gel Science and Technology. Vol. 3: Application of Sol-Gel Technology. Massachusetts: Kluwer Academic.

[13] Viswanathan, V., T. Laha, K. Balani, A. Agarwal, and S. Seal. 2006. Challenges and Advances in Nanocomposite Processing Techniques. Material Science and Engineering Reports. 54: 121-285.

[14] Niesen, T. P., and M. R. De Guire. 2001. Review: Deposition of Ceramic Thin Films at Low Temperatures from Aqueous Solutions. Journal of Electroceramics. 6: 169-207.

[15] Tolstoi, V. P. 1993. Synthesis of Thin-layer Structures by the lonic Layer Deposition Method. Russian Chemical Reviews. 62: 237242.

[16] Tolstoy, V. P. 2006. Successive Ionic Layer Deposition. An Application in Nanotechnology. Russian Chemical Reviews. 75: 161-175.

[17] Crespilho, F. N., V. Zucolotto, O. N. Oliveira Jr., and F. C. Nart. 2006. Electrochemistry of Layer-by-Layer Films: A Review. International Journal of Electrochemical Science. 1: 194-214.

[18] Decher, G. 2012. Multilayer Thin Films-Sequential Assembly of Nanocomposite Materials. Vol 2. Weinheim: Wiley-VCH.

[19] Pathan, H. M., and C. D. Lokhande. 2004. Deposition of Metal Chalcogenide Thin Films by Successive Ionic Layer Adsorption and Reaction (SILAR) Method. Bulletin of Material Science. 27: 85-111.

[20] Korotcenkov, G., V. Tolstoy, and J. Schwank. 2006. Successive Ionic Layer Deposition (SILD) as a New Sensor Technology: Synthesis and Modification of Metal Oxides. Measurement Science and Technology. 17: 1861-1869.

[21] Tolstoy, V. 1997. The Peroxide Route of the Successive Ionic Layer Deposition Procedure for Synthesis Nanolayers of Metal Oxides, Hydroxides and Peroxides. Thin Solid Films. 307: 10-13.

[22] Tolstoi, V. P. 2009. New Routes for the Synthesis of Nanocomposite Layers of Inorganic Compounds by the Layer-by-Layer Scheme. Russian Journal of General Chemistry. 79: 2578-2583.

[23] Tolstoy, V. P., and E. V. Tolstobrov. 2002. The Synthesis of Bi-VO-containing Nanolayers on Silica Surfaces by the Successive Ionic Layer Deposition Technique. Solid State lonics. 151: 165-169.

[24] Gulina, L. B., and V. P. Tolstoy. 2003. Synthesis by SILD of $\mathrm{Sn}_{0.6} \mathrm{MoO}_{\mathrm{y}} \cdot \mathrm{nH}_{2} \mathrm{O}$ Nanolayers on Silica. Thin Solid Films. 440: $74-$ 77.

[25] Gulina, L. B., and V. P. Tolstoi. 2004. Synthesis on Silica Surface by the Ionic Deposition Technique of Nanolayers of
Heteropolycompounds on the Basis of Phosphomolybdic Acid. Russian Journal of General Chemistry. 74: 327-330.

[26] Tolstoy, V., L. Gulina, G. Korotcenkov, and V. Brinzari. 2003. Synthesis of Nanolayers of Hybrid-type Hydroxo-SnOH and Heteropoly- $\mathrm{H}_{x} \mathrm{PW}_{y} \mathrm{O}_{z}$ Compounds on Silica Surfaces by Successive Ionic Layer Deposition Method. Applied Surface Science. 221: 197-202.

[27] Semischenko, K. B., I. V. Stepanenko, L. B. Gulina, and V. P. Tolstoi. 2011. Synthesis and Study of Cerium(IV) Polytungstate Nanolayers. Russian Journal of General Chemistry. 81: 10751077.

[28] Kramarenko, E. A., L. B. Gulina, I. V. Chernyshova, and V. P. Tolstoi. 2007. In $\ln _{0.22} \mathrm{SnS}_{0.33}(\mathrm{OH})_{4}$ Nanolayers Synthesized by the Layer-by-Layer Technique. Russian Journal of General Chemistry. 77: 987-989.

[29] Korotcenkov, G., V. Macsanov, V. Tolstoy, V. Brinzari, J. Schwank, and G. Faglia. 2003. Structural and Gas Response Characterization of Nano-size $\mathrm{SnO}_{2}$ Films Deposited by SILD Method. Sensors and Actuators B. 96: 602-609.

[30] Korotcenkov, G., S. D. Han, B. K. Cho, and V. Tolstoy. 2009. Structural Characterization and Phase Transformations in Metal Oxide Films Synthesized by Successive Ionic Layer Deposition (SILD) Method. Processing and Application of Ceramics. 3: 19-28.

[31] Kohl, D. 1990. The Role of Noble Metals in the Chemistry of Solid State Gas Sensors. Sensors and Actuators B. 1: 158-165.

[32] Korotcenkov, G. 2005. Gas Response Control Through Structural and Chemical Modification of Metal Oxides: State of the Art and Approaches. Sensors and Actuators B. 107: 209-232.

[33] Tolstoy, V., and E. Tolstobrov. 2004. Synthesis of "Hybrid" $\mathrm{Ag}_{\mathrm{x}} \mathrm{O} \cdot \mathrm{MnO}_{2} \bullet \mathrm{nH}_{2} \mathrm{O}$ Metal Oxide Nanolayers by Ionic Deposition. Russian Journal of General Chemistry. 74: 360363.

[34] Korotcenkov, G., L. Gulina, B. K. Cho, S. H. Han, and V. Tolstoy. 2011. $\mathrm{SnO}_{2}$-Au Nanocomposite Synthesized by Successive Ionic Layer Deposition (SILD) Method: Characterization and Application in Gas Sensors. Materials Chemistry and Physics. 128: 433-441.

[35] Gulina, L. B., V. P. Tolstoi, and E. V. Tolstobrov. 2010. Agx $-\mathrm{SnO}_{2}$ Nanocomposite Layers Synthesized by lonic Layer Deposition Onto Silica Surface. Russian Journal of Applied Chemistry. 83: 1525-1528.

[36] Tolstoi, V. P., and L. B. Gulina. 2008. Layers of xCuS- $\mathrm{SiO}_{2} \cdot \mathrm{nH}_{2} \mathrm{O}$ Nanocomposite, Synthesized by the Layer-by-Layer Technique. Russian Journal of General Chemistry. 78: 518520.

[37] Tolstoi, V. P., and L. B. Gulina. 2008. $\mathrm{Sb}_{2} \mathrm{~S}_{3}-\mathrm{SiO}_{2}$ Nanocomposite Layers Synthesized Using the Layer-by-Layer Technique. Russian Journal of Applied Chemistry. 81: 10681070.

[38] Berga, H. E., and W.O. Roberts (eds.). 2005. Colloidal Silica: Fundamentals and Applications. Boca Raton: CRC Press.

[39] Tolstoy, V., S. D. Han, and G. Korotcenkov. 2010. Chapter 9: Successive Ionic Layer Deposition (SILD): Advanced Method for Deposition and Modification of Functional Nanostructured Metal Oxides Aimed for Gas Sensor Applications. In: Umar, A., and Y.B. Hahn (eds.) Metal Oxide Nanostructures and Their Applications, Vol. 3, Applications (Part 1). Stevenson Ranch: American Scientific Publishers. 384-436.

[40] Korotcenkov, G. (ed.). 2010-2013. Chemical Sensors. Vols. 16. New York: Momentum Press.

[41] Korotcenkov, G., B. K. Cho, L. Gulina, and V. Tolstoy. 2009. Ozone Sensors Based on $\mathrm{SnO}_{2}$ Films Modified by $\mathrm{SnO}_{2}-\mathrm{Au}$ Nanocomposites Synthesized by the SILD Method. Sensors and Actuators B. 138: 512-517.

[42] Korotcenkov, G., B. K. Cho, V. Brinzari, L. Gulina, and V. Tolstoy. 2014. Catalytically Active Filters Deposited by SILD Method for Inhibiting Sensitivity to Ozone of $\mathrm{SnO}_{2}$-based Conductometric Gas Sensors. Ferroelectrics. 459: 46-51.

[43] Korotcenkov, G. 2013. Handbook of Gas Sensor Materials, Vols. 1-2. New York: Springer. 
[44] Jiang, S. P., Z. Liu, and Z. Q. Tian. 2006. Layer-by-layer SelfAssembly of Composite Polyelectrolyte-Nafion Membranes for Direct Methanol Fuel Cells. Advanced Matererials. 18: 1068-1072. 